\title{
Development of an algorithm for selecting the optimal set of tools and techniques for Agile project management in industry and engineering
}

\author{
V.V. Andreev, S.N. Malozemov \\ vyach.andreev@mail.ru | malozemovsage@mail.ru \\ Nizhny Novgorod State Technical University n.a. R.E. Alekseev, Nizhny Novgorod, Russia
}

\begin{abstract}
Continuous development and the increase of the safety requirements in the field of engineering and industry, as well as the need to comply with the planned timing and costs of the projects require the use of modern approaches to the management of complex engineering systems and their interaction. To achieve the optimal balance between the deadlines and the resources expended, a project approach is used in world practice. One of the new methods of the project approach is Agile management. The use of Agile project management in industry and engineering requires a systematic adaptation of implementation approaches, taking into account internal requirements, risks and organizational characteristics, and is due to the high complexity of decision-making. The paper considers an approach to the formation of a generalized algorithm for the optimal set of tools selection for Agile project management in industry and engineering based on system analysis methods. This algorithm is designed to provide decision support for the selection of the most suitable tools and techniques for Agile project management with a view to their successful implementation.
\end{abstract}

Keywords: decision-making algorithm, system analysis, project, Agile management, risk, management tools.

\section{Introduction}

Successful implementation of projects is largely due to competent, modern management. Today, there are many methods and approaches to project management. One of these approaches is Agile, which has proven itself in IT projects and in the banking sector. The first results of applying Agile approach in industry and engineering showed that using Agile similar to IT projects is impractical due to the different specifics of the activity and the impossibility of using a number of tools and techniques. When introducing this method in engineering and industry, it becomes difficult to select the optimal set of Agile tools and techniques. The problem is due to the large number of possible options and the lack of experience in the application of Agile project management in this area. To determine the tools and techniques of Agile, we need a mathematical method to optimize the decision-making process for selecting a set of tools and techniques.

The purpose is to determine the function and develop an algorithm for the optimal set of Agile management tools selections for a specific project.

\section{Correlation of sets of risks and tools}

Based on the existing experience of using Agile in various projects, we define many basic Agile tools and techniques, forming them into a specific data table with a description (table 1).

Table 1. Agile tools and techniques examples

\begin{tabular}{|c|l|}
\hline № & \multicolumn{1}{|c|}{ Tool name } \\
\hline 1 & Retrospective \\
\hline 2 & Poker planning \\
\hline 3 & Work speed estimation \\
\hline 4 & Work in one room \\
\hline 5 & Product backlog \\
\hline 6 & Task board \\
\hline
\end{tabular}

Next, we compile a systematic list of typical project risks in industry and engineering (table 2) [1-3].

Table 2. Examples of typical project risks

\begin{tabular}{|c|l|}
\hline № & \multicolumn{1}{|c|}{ Risk name } \\
\hline 1 & Conflicts of goals and interests between stakeholders \\
\hline 2 & Delays due to the change of performers \\
\hline 3 & $\begin{array}{l}\text { Changing customer requirements in the later stages } \\
\text { of the project }\end{array}$ \\
\hline 4 & Conflicts within the team \\
\hline 5 & Implicit dependencies with other projects \\
\hline 6 & Excessive product complexity \\
\hline 7 & The need for unique experts \\
\hline
\end{tabular}

Thus, we get 2 sets of project tools and project risks. To determine the correlation of sets of risks and tools, we apply the Swiss Cheese model and the Bow-tie model. The Swiss Cheese model demonstrates the principle of multilevel protection against possible incidents, the Bow-tie model determines the need to influence both the causes and consequences of events. Agile tools designed to manage the project can serve as preventive measures, monitoring and control tools, remedies for recovery and mitigation. The principle of the correlation of risks and tools is presented in Fig. 1. The formation of correlation between the elements of sets is carried out by the expert method, based on the experience of using Agile tools, personal professional experience in implementing projects in the selected field, taking into account the characteristics of the organization and the external environment.

In this correlation, we see that one risk can be blocked by different instruments; one tool can cover different risks. To select specific tools, we introduce expert assessments project criteria: time (team's time spent on using the tool) (t), budget (including additional resources or competencies) (b), team satisfaction level (u). Each criterion is assigned a range of possible weight, taking into account pre-calculated costs [4-7]. 


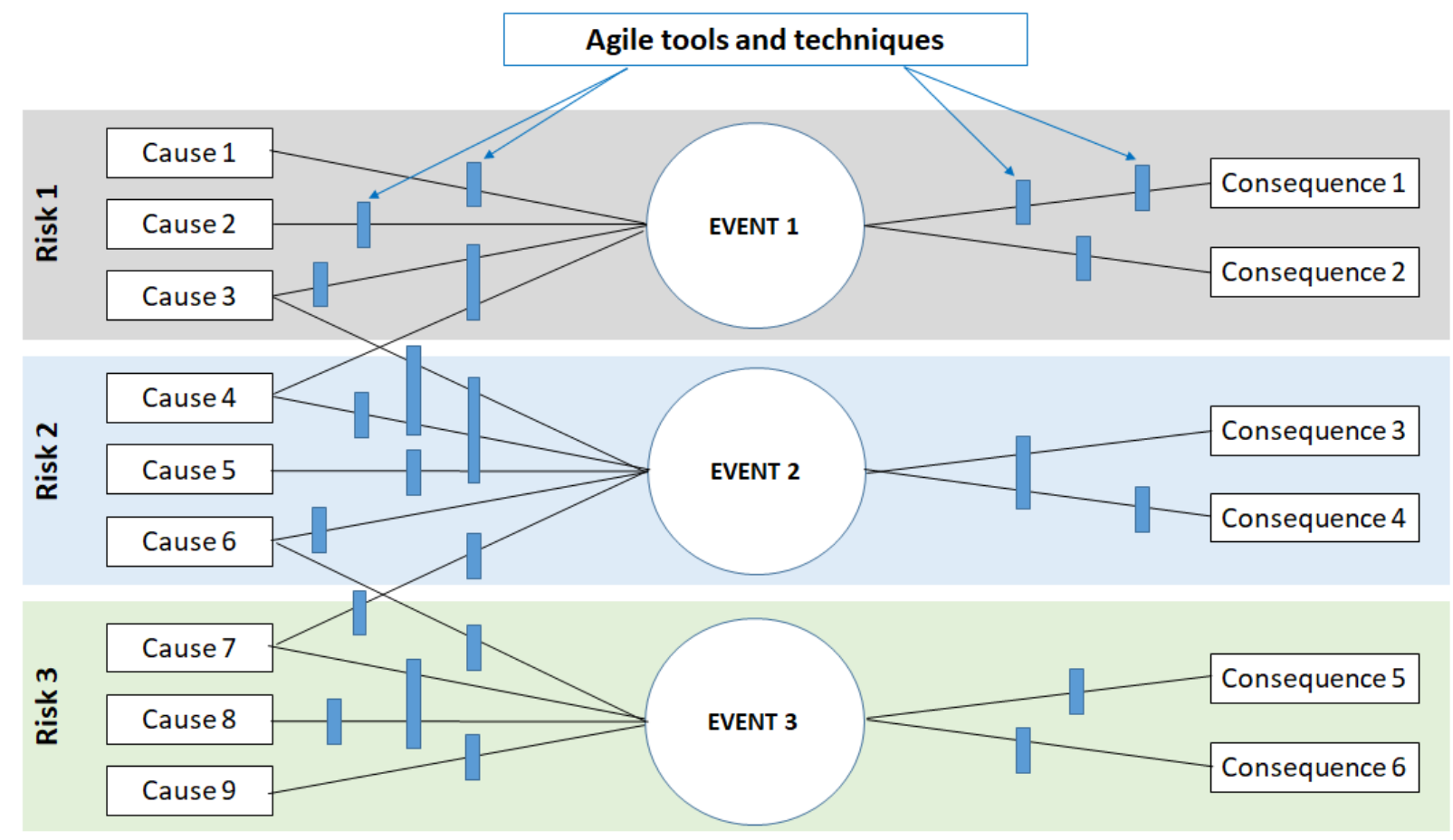

Fig. 1. The principle of the correlation of risks and tools

\section{Application of system analysis methods}

There are many decision-making methods. Due to the presence of several criteria in the tools and the presence of links between the sets of risks and tools, we will choose the main methods of system analysis, which we will use when selecting the optimal set of tools. For Agile approach, consider a group of descriptive models (that is, simulate human behavior in a decision-making situation). Based on what we will build a phased decision-making algorithm. At each stage, depending on the task, we will use the most appropriate method.

The methods that we will use in the definition of a function are: the matrix method of multicriteria analysis, the logical-linguistic model, the cause-effect model, the method of pairwise comparisons, the axiomatic method. The matrix method of multicriteria analysis allows one to find a balanced estimate through the construction of matrices of values and the importance of alternatives.

A logical-linguistic model will make it possible to determine the most suitable set of all possible risks from the set of possible tools. In this model, when making a decision, there is no way to consider the importance of the element (risk), which affects the accuracy of the decision.

With a causal decision-making model, a function is determined with a possible consideration of the importance of the element. With this model, multicriteria analysis involves comparing a number of criteria with possible options, including alternative ones that arise in the process of solving the tasks.

\section{Decision making algorithm for tools selection}

Define a general decision making algorithm for tools selection. At the first stage, the decision maker (DM) selects the possible risks that may arise during the implementation of the project, and also sets the limit values and factors of importance of the project parameters (time, budget, team satisfaction). We get the source data:

- preset project parameters $\left(\mathrm{t}_{\mathrm{pp}} ; \mathrm{b}_{\mathrm{pp}} ; \mathrm{u}_{\mathrm{pp}}\right)$;

- project risk list (set ri);

- importance factor (w).

Through the selected risks, the tools are determined based on predefined relationships. Get the matrix of $\mathrm{M}$ relations (risk - tool) $-\mathrm{m}_{\mathrm{ri}}$ (matrix element showing the presence of communication, possibly in the binary system: 1 -connection is, 0 -communication is not).

Each tool consists of three previously defined criteria and $(t ; b ; u)$. We divide the matrix of connections into three matrices for each of the criteria. We get three matrices with values that have previous relations (risk - tool).

We use the method of pairwise comparisons to find the smallest values in the first two matrices and the largest values in the third matrix that evaluates the qualitative characteristic - team satisfaction.

To find a set of tools on each of the matrices, a condition must meet, each risk must be assigned a minimum value (matrix element). We get the column of minimum values in two matrices and the maximum value in the third matrix.

We use the logical-linguistic decision-making model. We transform the given project parameters into a vector whose starting point is 0 and tends to a point - the given project parameters (xtbu), according to each of the criteria, these will be the points $U(t), U(b), U(u)$. Then get many alternative solutions $\mathrm{P}(\mathrm{p} 1, \mathrm{p} 2, \ldots, \mathrm{pn})$, where, for example: $\mathrm{p} 1=\mathrm{u} 1+\mathrm{u} 2+\mathrm{u} 4, \mathrm{p} 2=\mathrm{u} 6+\mathrm{u} 9, \mathrm{p} 3=\mathrm{u} 3+\mathrm{u} 4+\mathrm{u} 7$.

Next, we check that all the parameters are fulfilled for each of the alternative solutions found and find the optimal solution. We will use the causal decision-making model. The criteria $\mathrm{c}(\mathrm{c} 1=\mathrm{t}, \mathrm{c} 2=\mathrm{b}, \mathrm{c} 3=\mathrm{u})$ were determined in advance, we introduce the correction factor $(\mathrm{cr} 1=1, \mathrm{cr} 2=$ 
$1, \operatorname{cr} 3=-1)$ for the convenience of comparison, $\mathrm{W}$ importance of the element $\left(\mathrm{w}_{1}, \mathrm{w}_{2}, \mathrm{w}_{3}\right)$.

Now, for each of the alternatives, we make a separate assessment for the entire range of criteria $\mathrm{x}\left(\mathrm{x}_{\mathrm{t}}, \mathrm{x}_{\mathrm{b}}, \mathrm{x}_{\mathrm{u}}\right)-$ table 3 .

Table 3. Decision matrix for each criterion
\begin{tabular}{|c|c|c|c|c|c|c|}
\hline & $\mathrm{p} 1$ & $\mathrm{p} 2$ & $\ldots$ & $\mathrm{pn}$ & $\mathrm{cr}$ & $\mathrm{W}$ \\
\hline $\mathrm{t}$ & $\mathrm{xt} 1$ & $\mathrm{xt} 2$ & $\ldots$ & $\mathrm{xtn}$ & 1 & $\mathrm{w}_{1}$ \\
\hline $\mathrm{b}$ & $\mathrm{xb} 1$ & $\mathrm{xb} 2$ & $\ldots$ & $\mathrm{xbn}$ & 1 & $\mathrm{w}_{2}$ \\
\hline $\mathrm{u}$ & $\mathrm{xu} 1$ & $\mathrm{xu} 2$ & $\ldots$ & $\mathrm{xun}$ & -1 & $\mathrm{w}_{3}$ \\
\hline & $\mathrm{R} 1$ & $\mathrm{R} 2$ & $\ldots$ & $\mathrm{Rn}$ & \multicolumn{2}{c}{} \\
\cline { 2 - 7 }
\end{tabular}

Thus, the most appropriate solutions $\mathrm{p}_{\mathrm{j}}$ will be determined through the function:

$$
R=F(X, W) \text {, }
$$

where $X$ is the vector of values $x_{\mathrm{cj}}\left(\mathrm{x}_{\mathrm{tj}}, \mathrm{x}_{\mathrm{bj}}, \mathrm{x}_{\mathrm{uj}}\right), \mathrm{cr}-$ correction factor, $\mathrm{W}$ - element importance, $\mathrm{F}$ - value convolution function.

For the most balanced assessment, we can consider the sum of the products of the criterion and importance:

$$
R=\sum_{i=1}^{n} p\left(x_{c i} \cdot w_{i}\right)
$$

When finding the smallest number of alternative solutions (satisfying the given parameters), we check their fulfillment of the conditions without taking into account the correction factor:

$$
\begin{aligned}
& p_{i}\left(t_{i}, b_{i}, u_{i}\right) \\
& \leq p_{i}\left(t_{p p}, b_{p p}, u_{p p}\right) .
\end{aligned}
$$

That is, some solution $\mathrm{R}$ must satisfy the conditions: the values of $t$ and $b$ - should be no more than the specified project parameters and the minimum possible, and the value $\mathrm{u}$ - no less than the specified project parameter and the maximum possible.

We use the axiomatic method to identify the correct solution.

$$
\begin{gathered}
X\left(t_{p p} ; b_{p p} ; u_{p p}\right) \geq p(t ; b ; u), \\
p(t ; b ; u)=\sum_{i=1}^{n} U_{i}(t ; b ; u), X\left(t_{p p} ; b_{p p} ; u_{p p}\right)-\text { set }
\end{gathered}
$$
parameters, $\mathrm{i}-$ tool serial number.

$$
\begin{aligned}
& p(t ; b ; u) \\
& =\left\{\begin{array}{l}
\sum_{i=1}^{n} U(t) \leq x\left(t_{p p}\right) ; \\
\sum_{i=1}^{n} U(b) \leq x\left(b_{p p}\right) ; \\
\sum_{i=1}^{n} U(u) \leq x\left(u_{p p}\right) .
\end{array}\right.
\end{aligned}
$$

If there are several alternatives, it is possible to use the pairwise comparison method to find the most optimal solution.

Having found the optimal solution in a list form, it is necessary to ensure the conclusion of a set of tools for a specific project, with a description of each tool and the necessary time, budget and impact on team satisfaction.

As a result, the DM makes the final decision on the use of these tools and forms a project management plan (management action plan) based on the selected tools. Fig. 2 shows the general decision making algorithm for selecting tools.

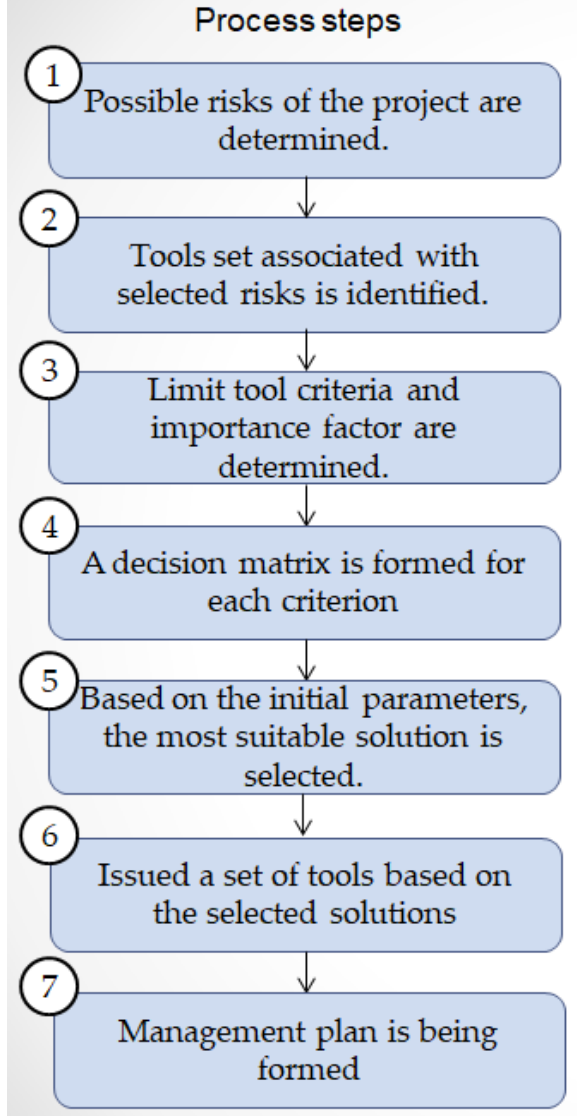

\section{Initial data}

A systematic list of typical design risks in industry and engineering (set $\mathrm{r}_{\mathrm{i}}$ )

A list of Agile tools, matrix $\mathrm{M}$ relations of risks and tools

Assessment of set of tools according to the criteria (time, costs, team satisfaction), selection of $\mathrm{t}_{p p} ; \mathrm{b}_{p p} ; \mathrm{u}_{p q} ; \mathrm{w}_{1} ; \mathrm{w}_{2} ; \mathrm{w}_{3}$

Set of solutions $\mathrm{P}(\mathrm{p} 1, \mathrm{p} 2, \ldots, \mathrm{pn})$, where, e.g.: $\mathrm{p} 1=\mathrm{u} 1+\mathrm{u} 2+\mathrm{u} 4, \mathrm{p} 2=\mathrm{u} 6+\mathrm{u} 9, \mathrm{p} 3=\mathrm{u} 2+\mathrm{u} 7$

Function $\mathrm{R}=\mathrm{F}(\mathrm{X}, \mathrm{W})$, condition $\mathrm{X}\left(\mathrm{t}_{\mathrm{pp}} ; \mathrm{b}_{p p} ; \mathrm{u}_{\mathrm{pp}}\right) \geq$ $\mathrm{p}(\mathrm{t} ; \mathrm{b} ; \mathrm{u})$, importance factor $\mathrm{w}$, pair comparison method

Disclosure $\mathrm{P}_{\text {opt }}$ of the list of tools

Selected tools, methodological support for decision makers

Fig. 2. Decision making algorithm for tools selection 


\section{Recommendations for using the tool selection algorithm}

As part of the application of this algorithm, the difficult questions will be:

- initial definition of the scope of application of Agile project management in engineering and industry;

- determination of the importance of the criterion and its value for qualitative indicators (for example, the impact on team satisfaction) in determining the overall indicator;

- combination of a formalized algorithm for selecting tools and difficult formalized practical experience of decision makers in the field of project management.

First, a preliminary analysis of the applicability of Agile to specific projects is needed. For many types of activities (for example, construction and installation works, commissioning) Agile is not applicable. For quick analysis, Agile applicability models (filters) can be used. However, there are currently no filters for projects in the field of industry and engineering. Analytical work is necessary to supplement the existing models of Agile applicability with criteria that are essential for the implementation of projects in the field of industry and engineering. Effective application of the obtained algorithm is possible only in the field of applicability of Agile.

Secondly, the project team, project stakeholders, and the expert community can be involved in working with criteria of tools. It is necessary to develop a common scale of assessments of tools, considering various points of view. The value of the criteria for each tool must be determined taking into account the specifics of the organization's activities and corporate culture (for example, in one project the "retrospective" tool will be a significant improvement and will positively affect team satisfaction, as in others it will be an obstacle). Multicriteria analysis should be complemented by significant methodological support. Statistics on other projects of companies in this field of activity can also be used.

Thirdly, it is necessary to provide for the possibility of choosing some Agile management tools, or to adjust the final set based on the decision of the project methodologist. If there is a lot of informal experience in using some Agile tools in a given company, an understanding of the internal corporate culture, a large number of quality criteria and implicit restrictions, various alternative solutions can be evaluated using the presented algorithm. In this case, it will also be useful to use readymade lists of data (risks / tools) of the algorithm. In the absence of significant experience in the company using Agile, the algorithm should be applied in its original form [12-14].

In addition, when making decisions on tools selection, various kinds of misconceptions are possible. One of the sources of error in decision-making is premature generalization. No matter how universal the tools are, it is impossible to rely on the consideration of criteria on the basis of a perfectly successful project from another field of activity. Also misconception can be attributed to reasoning by analogy. In some cases, not all instruments and risks can be evaluated by analogy in different projects. An example about the "retrospective" tool was described above.

Based on the decision-making methods used, it is recommended to approach each project individually for the optimal Agile tools selection in industry and engineering. Use the generated algorithm and systematic lists of risks, tools to improve the quality of managerial decision-making. Pay special attention to the methodological work on the formation of criteria and factors of importance for each of them. In some projects, it will be advisable to consider a wider range of alternatives, which will minimize the risks of the project and choose the optimal solution in terms of design parameters.

\section{Conclusions}

The paper investigates the decision-making process when choosing tools for Agile project management. In the framework of this article, the following issues were considered:

- determining the principle of the Correlation of sets of risks and tools;

- definitions of the decision-making function for applying the Agile tools;

- development of an algorithm for the optimal set of Agile tools selection in industry and engineering.

To determine the function and develop the algorithm, methods of system analysis were used. At the same time, further application of system analysis methods for making multi-criteria decisions in terms of determining the scope of applicability of flexible project management and working with tool criteria also looks perspectively.

The paper gives recommendations on the application of the obtained algorithm and its further development. Two cases of application are considered:

- subject to your organization has Agile knowledge and experience in this field;

- subject to initial application of Agile project management approaches.

The results obtained can be applied to implement Agile approaches to project management in industry and engineering at the stages of initiation and planning. Using the right Agile tools and techniques can help you achieve your project goals on time and with significant resource savings.

\section{Acknowledgments}

The study was supported by the RFBR, grant № 19-0700455

\section{References}

[1] AGILE Alliance [Electronic resource] - (C2020 Agile Alliance - URL: https:/www.agilealliance.org/ (date of access: 15.03.2020).

[2] «Project Management Assessment and Development Center » [Electronic resource] - (C) ANO «CADPM» - URL: https://www.isopm.ru/ (date of access: 15.03.2020). 
[3] Agile Russia [Electronic resource] - URL: http://agilerussia.ru/category/methodologies/ (date of access 17.03.2020).

[4] Krogerus Michael Book of solutions. 50 models of strategic thinking / Michael Krogerus, Roman Cheppeler - Publisher: Olymp-Business, 2018 - 208 p. - ISBN 978-5-9693-0309-6, 978-3-0369-5529-2.

[5] «Three-level Russian instrumental project management model (RIM-M)» [Electronic resource] - URL: https://rim-iii.postach.io/ (date of access 18.03.2020).

[6] Informatika [Electronic resource] // Bow-tie Model URL: http://5informatika.net/ (date of access 17.03.2020).

[7] GOST R ISO / IEC 31010-2011 Risk management. Risk assessment methods. [Electronic resource] C Codex JSC, $2020 \quad$ - URL: http://docs.cntd.ru/document/gost-r-iso-mek-310102011 (date of access 17.03.2020).

[8] Podinovsky V.V. Ideas and methods of the theory of the importance of criteria in multicriteria decisionmaking problems / V.V. Podinovsky - M: Science, 2019 - 103 p. - ISBN 978-5-02-040241-6.

[9] Kochkina M.V. Analysis of multicriteria management decision-making methods (on the example of the task of selecting suppliers of material and technical resources) / M.V. Kochkina, A.N. Karamyshev, I.I. Makhmutov, A.G. Isavnin, A.K. Rosenzweig Naberezhnye Chelny: Publishing and Printing Center NCHI K (P) FU, 2017 - 31 p. - UDC 338.2; 658.7.

[10] Kravchenko T.K., Druzhayev A.A. Adaptation of the ELECTRE family methods for inclusion in the expert decision support system [Electronic resource] / T.K. Kravchenko, A.A. Druzhayev // Business Informatics. - 2015. - № 2 (32). - URL: http://cyberleninka.ru /article/n/adaptatsiya-metodov-semeystva-electredlyavklyucheniya-v-ekspertnuyu-sistemupodderzhki-prinyatiya-resheniy (date of access: 18.03.2020).

[11]Kozlov, V.N. System analysis, optimization and decision- making. Textbook / V.N. Kozlov. - M.: Prospect, 2016. - 173 p. - ISBN: 978-5-392-20185-3.

[12] Agafonov V.A. System analysis in strategic management. Tutorial. / V.A. Agafonov - M: Rusyns, 2020 - 229 p. - ISBN: 978-5-4365-4407-6.

[13] Madera A.G. Mathematical models and decisionmaking in management: A guide for top managers / A.G. Madera - Vol. 3, stereotype - M: Lenand, 2019 - 688 p. - ISBN 978-5-382-01845-4.

[14]Zak, Yu.A. Decision making in fuzzy and blurry data: Fuzzy-technology / Yu.A. Zak - Vol. 2 - M: Lenand, 2016 - 352 p. - ISBN 978-5-9710-3411-7.

\section{About the autors}

Vyacheslav V. Andreev, head of the department "Nuclear Reactors and Power Plants", Doctor of Technical Sciences, Professor, NNSTU n.a. R.E. Alekseev. E-mail: vyach.andreev@mail.ru.

Sergei N. Malozemov, graduate student of the department "Nuclear Reactors and Power Plants", NNSTU n.a. R.E. Alekseev. E-mail: malozemovsage@mail.ru. 